\title{
Can Psychotherapists Improve Help Seeking Behavior: A Case Study of Accra Polytechnic Students
}

\author{
Evelyn Ekua Bentil ${ }^{1,2}$ \\ ${ }^{1}$ The Guidance and Counseling Department, Accra Polytechnic, Accra, Ghana \\ ${ }^{2}$ Department of Psychology, University of Ghana, Legon, Accra, Ghana
}

Email address:

Lynnevebentil@hotmail.com

\section{To cite this article:}

Evelyn Ekua Bentil. Can Psychotherapists Improve Help Seeking Behavior: A Case Study of Accra Polytechnic Students. Psychology and Behavioral Sciences. Vol. 4, No. 2, 2015, pp. 64-70. doi: 10.11648/j.pbs.20150402.15

\begin{abstract}
The aim of this study was to find out if psychotherapists could improve help seeking behavior. The research instruments used were validated and standardized instruments, namely, the General Help Seeking Questionnaire-Vignette (GHSQ-V) and the Actual Help Seeking Questionnaire (AHSQ). These instruments were used to measure the participants' general help seeking intentions and actual help seeking behavior respectively. A demographic questionnaire was also used to determine the demographic variables of the participants. The population for this research was students who had been enrolled in Accra Polytechnic, in the Republic of Ghana. A repeated measures design was used to evaluate an invention procedure involving the use of psychotherapeutic strategies to improve help seeking intentions and behavior. It was hypothesized that participants will have an increase in their help seeking intentions and report more help seeking behavior after the intervention. The study's hypotheses were analyzed with the Wilcoxon Matched-Pairs Singed-Rank ( $T$ ) Test with the aid of the version 17 of the Statistical Package for Social Sciences (SPSS V 17). The results indicated that psychotherapists could improve help seeking behavior. The limitations and implications of the study are then discussed. Areas for further research are also recommended.
\end{abstract}

Keywords: Help Seeking, Accra Polytechnic, Interventions, Repeated Measures Design, Psychotherapy, Psychotherapists, Case study, behavior

\section{Introduction}

There is a discrepancy between the need for mental health treatment and the utilization of such services. Several studies (Appiah-Poku, Laugharne, Mensah, Osei and Burns, 2004; Boyraz, Horne, Owens, \& Armstrong, 2013; Read \& Doku, 2012; Schreiber, Maercker \& Renneberg, 2010; Wang, Berglund, Kessler, Olfson, Pincus \& Wells, 2005) have revealed that typically people tend to underutilize professional mental health services. Help seeking behavior is perceived as an index of dependence and a degrading activity which is better avoided (Nelson-Le Gall, 1985).

Barriers to help seeking behavior which have been reported by researchers include the fear of negative repercussion, (Kessler, Brown \& Broman, 1981), privacy/issues of confidentiality, embarrassment, lack of trust (Garcia \& Rodriguez, 1989), the characteristics/competence of the therapist (Turner, Midgley, Meyer, Gheen, Anderman, Kang \& Patrick, 2002), being unaware of services available or how to get it, socioeconomic factors, (Miranda \& Green, 1999), lack of perceived need, (Mackenzie, Pagura \& Sareen, 2010), skepticism about effectiveness (Auglin, Alberti, Link \& Phelan, 2008), stigma, (Britten, 1998), age, (Gulliver, Griffiths \& Christensen, 2010) and gender, (Ofori-Atta, Cooper, Akpalu, Osei, Doku, Lund, et al., 2010). Some of these factors listed above could play dual role in help seeking behavior. They could facilitate or hinder help seeking behavior. These include age and gender.

Strategies for promoting help seeking behavior have been varied. Studies on improving help seeking behavior have suggested psycho-education (Barker, 2007) as an effective means of promoting help seeking attitudes/intentions. The use of seminar/workshop aimed at giving information on mental health and reducing the stigma associated with mental disorders has been known to promote help seeking intentions/attitudes/behavior (Santor, Poulin, LeBlanc and Kusumakar, 2006; Howerton, Byng, Campbell, Hess, Owens and Aitken 2007 and Kwong, 2011). The utilization of telephone and hot line services have been reported as useful in promoting help seeking behavior (Barker, 2007). Again, engaging peer promoters to encourage peers to go for therapy 
has resulted in an improvement in help seeking behavior. Psychotherapeutic techniques which have been employed to address barriers to help seeking attitudes have also been worthwhile (Gulliver, Griffiths, Christensen and Brewer, 2012) though they may not have much effect on help seeking behavior.

The services of a psychotherapist can be accessed in most general hospitals and psychiatric hospitals in Ghana. Most schools in Ghana, including tertiary institutions, also have clinical psychologists and/or counseling psychologists manning their counseling departments yet there is an indication that patronage of these services is low. Psychotherapeutic services provided in schools and some psychiatric hospitals are free of charge, hence, the issue of affordability is out of the question. There was therefore the need to research into how to improve help seeking behavior with psychotherapeutic strategies.

The questions of interest were?

- Why do some students refuse to seek psychological help when they need to?

- Can psychotherapeutic interventions improve help seeking behavior among students?

The goal of this study was to use psychotherapeutic techniques to reduce the barriers to mental health help seeking and increase beneficial help seeking engagements with psychotherapy.

\section{Theoretical Framework}

Help seeking behavior has been conceptualized by some researchers as a decision making process. Cornally and McCarthy (2011), identified four major component of help seeking behavior. These are: the antecedents to help seeking behavior, the defining attributes of help seeking behavior, the consequences of help seeking behavior, and the empirical referents of help seeking behavior.

Under the "antecedents to help seeking behavior" component, one has to recognize that a problem exists after which the individual will have to decide to seek help and then decide on the selection of a help source. The recognition of a problem is usually influenced by the presence and the characteristics of symptoms. A person's decision to seek help can be influenced by demographic characteristics of the individual like gender norms, age, cultural norms and values (Cornally \& McCarthy, 2011). Help seeking behavior may also depend on factors like one's past experience with help seeking, one's personal attitudes and also one's beliefs and perceptions about the medical system (Pattenden, Watt, Lewin, $\&$ Standord, 2002) and (Moloczij, McPherson, Smith \& Kayes, 2008). The source of help can be a member of one's family, a friend, a colleague at work or a professional.

Under the "defining attribute" component, help seeking behavior is perceived as having three attributes. These attributes include problem focused, intentional action and interpersonal interaction (Cornally \& McCarthy, 2011). The presence of a problem is the basic attribute of any help seeking behavior. Help seeking behavior is deemed as an intentional action because it is a planned behavior. Also it is an interpersonal interaction since it involves the interaction of two or more people.

Help seeking behavior could have positive or negative consequences. The problem presented could get resolved or otherwise.

Help seeking behavior involves empirical referents. These are classes or categories of actual phenomena that by their existence or presence demonstrate the occurrence of the concept itself. For example the number of available formal sources of help in an area is enough to predict that people do engage in formal help seeking (Cornally \& McCarthy, 2011).

Kwong (2011) conducted a study with the aim of increasing access to mental health services by depressed Chinese-American patients. Six thousand and sixty-five (6065) patients were identified and screened for depression. Out of those who tested positive for depression, only 57 of them agreed to participate in the study. A semi-structured questionnaire which contained questions from the Explanatory Model Interview Catalogue was used to elicit responses from the participants including patterns of help seeking behavior and barriers to receiving mental health care. Reported barriers included factors relating to the Chinese culture, attitudes towards the medical system, concerns about treatment cost. The study suggested that psycho-educational strategies must be developed to educate patients on mental health issues.

The study had a refusal rate of $55 \%$ and this could have affected the study outcome in that it is possible that those who refused to participate had characteristics which were different from that of those who agreed to participate in the study. It was however beneficial that the researcher involved those who refused in a refusal study.

Gulliver, Griffiths, Christensen and Brewer (2012), conducted a review of studies done on help seeking interventions for depression, anxiety and general psychological distress using six published research of randomized controlled trials investigating eight different interventions for help seeking behavior. Gulliver, Griffiths, Christensen and Brewer (2012), realized that six out of the eight studies used interventions that provided information on mental health literacy. Of these, five studies measured and reported a significant improvement in help seeking attitudes in the intervention group compared with that of the control group.

For the other three studies, there were no differences between the control and experimental groups. Two of the three studies Gulliver, Griffiths, Christensen and Brewer (2012), reviewed which used interventions that provided information with the aim of de-stigmatizing mental illness, showed an improvement in help seeking attitudes of the subjects, while one did not. One study that also measured help seeking behavior did not find significantly greater help seeking behavior among the intervention group compared with that of the control group. All three studies which provided interventions targeted on giving information on various sources of help seeking, reported a significant improvement in 
help seeking attitudes among the intervention group compared with the control group. One of the studies measured behavior and reported no significant effect of the intervention on this aspect of help seeking.

Gulliver, Griffiths, Christensen and Brewer (2012), also reported that out of the two studies which used interventions using interviewer contact via telephone, one study demonstrated a significant increase in help seeking behavior in the intervention group when compared with the control, and one study did not. Again, the intervention strategy that gave subjects the opportunity to have some contact with consumers (via a pre-recorded video) was associated with a significant improvement in attitudes among members of the intervention group compared with that of the control group. Likewise, studies which used interventions that provided cognitive behavior therapy, and personalized feedback about the individual's symptoms significantly improved help seeking behavior in the comparison group compared with the control.

Gulliver, Griffiths, Christensen and Brewer (2012), thus concluded that from the studies they reviewed, it was evident that mental health literacy content was effective in improving help seeking attitudes in majority of the studies at post-intervention, but had virtually no effect on help seeking behavior but for the intervention that used cognitive behavior therapy to improve help seeking behavior. There was less evidence for other intervention types such as efforts to de-stigmatize or provide help seeking source information that they could promote help seeking intentions, attitudes or behavior. Hence, further research investigating the effects of interventions on help seeking attitudes, help seeking intentions, and help seeking behavior was recommended by Gulliver, Griffiths, Christensen and Brewer (2012).

Virtually no study has been conducted on interventions for improving young people's utilization of mental health care in Ghana. It was not clear from literature which interventions were capable of promoting the help seeking behavior of young people in Ghana. The shortcomings of the literature reviewed necessitated the institution of an intervention to ascertain whether psychotherapists could improve help seeking behavior using psychotherapy. This study therefore attempted using cognitive, insight and supportive therapies to improve the help seeking behavior.

The following were the study's hypotheses:

Hypothesis 1: Participants will have an increase in their help seeking intentions after the intervention.

Hypothesis 2: It was also hypothesized that participants will report an increase in their actual help seeking behavior after the intervention.

\section{Methodology}

\subsection{Sample/Population}

The population for this study was students who had been enrolled into various tertiary institutions in the Republic of Ghana. The study utilized a non-probability, convenience sampling method to select a tertiary institution (Accra
Polytechnic) and subsequently recruit eighteen participants from the institution for the study.

Participants recruited were representative of the three schools/faculties in the institution. The age of the participants ranged from 21 to 26 years with a mean age of 22 years. Thirteen of the participants were males while five were females. Six participants were in their first year, another six were in the second year of their program and another six in the third year. While 17 participants were unmarried, one participant was a member of an unmarried couple.

\subsection{Measures}

Validated instruments were used for this study. The General Help Seeking Questionnaire - vignette (GHSQ-V: Wilson, Deane, Ciarrochi \& Rickwood, 2002) was used to measure respondents' help seeking intentions. Higher scores on this scale indicate more intentions to seeking help. Respondents' recent actual help seeking behavior was measured with the aid of the Actual Help Seeking Questionnaire (AHSQ: Rickwood and Braithwaite, 1994). Higher scores on this scale indicate fewer help seeking behavior.

In addition to these instruments, a demographic information sheet was included to assess basic demographic information of the subjects. This information included, gender, age, course being pursued in the tertiary institution, marital status, and religion. The instruments were pilot studied before being used for the study.

\subsection{Study Area}

This study was conducted in Accra Polytechnic, a tertiary institution in the Greater Accra Region of the Republic of Ghana.

\subsection{Research Design}

This study is a repeated measures research design. Subjects acted as their own control. Subjects were tested before the intervention procedure to obtain the baseline scores and again tested after the intervention procedure with the same set of instruments.

\subsection{Data Collection/Procedure}

Participants were divided into three groups, according to their level. Each group was taken through the intervention separately. The intervention procedure was in three phases. Each phase took between one and eight weeks to complete. The intervention was done once a week. The aim of the first phase was to gather information on help seeking behavior, attitudes, intentions and barriers to care. The second phase was to address the barriers using psychotherapeutic techniques. The third phase was to gather information in order to evaluate the outcome of the study.

In phase one, the respondents were selected and divided into three groups (according to their level). During the first meeting, the members were made to introduce themselves after which the purpose of the meeting was given. They were assured confidentiality and the possibility of withdrawing 
from the study at any stage they wished. Participants were then made to fill a consent form after which the demographic questionnaire, GHSQ-V and the AHSQ, were administered to them. These instruments were presented to them randomly to minimize order effect on the study. The inventories yielded data on barriers to care and patterns of help seeking behavior of the respondents. The respondents were then made to free associate on mental health and what could prevent people from seeking mental health care. This information was noted down.

During phase two, techniques from insight, supportive and cognitive therapies were used. Barriers to mental health help seeking behavior were explored further. Barriers listed were discussed into details to obtain more information from the respondents. The identified barriers were then addressed. To address these, subjects were given insights into the various forms of psychological disorders and available psychotherapeutic options. They were also helped to list all the negative ideas and thoughts they had about mental health and seeking mental health care. After that, the cognitive restructuring technique was introduced to counter these dysfunctional thoughts, irrational ideas and other negative ideas about seeking mental health care.

The hypothesis and validity testing techniques which assess the hypothesis/validity of irrational ideas were also used to test the reality/validity of some of the respondents' negative ideas about mental health illness and available treatment options. Respondents were taken through retribution training. They were made to understand that the cause of mental problems was not only spiritual but could be purely psychological. Treatment fears were also challenged through the de-catastrophising technique of the cognitive therapy. The issue of stigma and other sensitive barriers to care (like treatment fears) were also addressed carefully. Using the guided discovery techniques, respondents were gradually led to realize the importance of mental health care. They were also made to compare the pros and cons of seeking mental health care.

All these were done in an environment where the subjects were made to relax, feel accepted and cared for so that they felt at ease to discuss concerns and problems as well as share experiences and feelings without the feeling of being judged. Members of the groups were made to understand that no input would be considered as wrong. They were made to understand that each person's opinion, no matter how negative it appeared, would be seen as unique and acceptable. One of the rules was that when someone was making an input, the others had to be quiet and listen to him or her. They were not to be rude or make comments. They had to wait for their turn.

Respondents were also given assignments to be completed before the next session. They were to use the journaling technique to record all their observations whilst performing the assignment.

For the last phase, the subjects were made to give a verbal report on the assignment which was given. The questionnaires were administered a second time after which the results were compared with the first set of questionnaires completed by the same group and analyzed.

\subsection{Data Analysis}

The Statistical Package for the Social Sciences (SPSS v 17.0) was used to analyze the data after which the Wilcoxon Matched-Pairs Signed-Ranks Test ( $T$ test) was used to test the hypotheses. This test was chosen because this research design was a repeated measures design. A non parametric test was chosen over its parametric equivalent because non parametric tests make less stringent demands of the data (Opoku, 2006).

The dependent variables were scores from the GHSQ-V and the AHSQ. The level of measurement of the instruments used in the data collection was ordinal and the sample was not randomly selected indicating that the sample is not homogenous. This gave preference of a non-parametric test like the Wilcoxon Matched-Pairs Signed-Ranks $(T)$ test over the parametric $T$ Test for Matched or Correlated Samples.

\subsection{Ethical Consideration}

Ethical issues relating to research were strictly adhered to. Using American Psychological Association's (APA) ethical code as guideline, permission was sought from the institution and individuals who were directly or indirectly involved in the study. Emails were sent to the authors of the various instruments used in this study to seek their permission to use them for this study before they were pilot tested and subsequently used for the study. Anonymity and confidentiality of respondents were ensured. No respondent was maltreated in any way. All literature sources that were consulted and used for the study have been duly acknowledged.

\section{Results/Discussion}

Hypothesis 1: "Participants will have an increase in their help seeking intentions after the intervention."

The purpose of this hypothesis was to find out whether psychotherapists could improve help seeking intentions with psychotherapy. The data collected was analyzed using the Wilcoxon Matched-Pairs Signed-Ranks $(T)$ Test with the aid of the SPSS software.

The means and standard deviations for the various groups (extracted from the SPSS output) are shown in Table 1.

Table 1. Means and Standard Deviation of Pre-Test and Post-Test Scores on Help Seeking Intentions

\begin{tabular}{lccc}
\hline Gender & Mean Score & Std. Dev. & Sample Size(n) \\
\hline Pre Test (GHSQ-V) & 245.2222 & 51.81251 & 18 \\
Post Test (GHSQ-V) & 301.6667 & 47.88344 & 18 \\
\hline
\end{tabular}

Source: Field Study

The data was further analyzed with the Wilcoxon Matched-Pairs Signed-Ranks ( $T$ ) Test to determine whether the differences in the means were significant.

Table 2 presents a summary table of the Wilcoxon Matched-Pairs Signed-Ranks (T) Test for the dependent 
variable.

Table 2. Summary Table of the Wilcoxon Matched-Pairs Signed-Ranks (T) Test Performed on the Data Presented in Table 1

\begin{tabular}{lcccc}
\hline Group & Mean Rank & Sum of Ranks & $\boldsymbol{T}$ & $\boldsymbol{p}$ (level of Significance) \\
\hline Pre Test (GHSQ-V) & 9.00 & 9.00 & & \\
Post Test (GHSQ-V) & 9.53 & 162.00 & -3.333 & $p<.0005$ (one tailed) \\
\hline
\end{tabular}

Source: Field Study

Again, Table 2 depicts that the computed value of $T$ for the GHSQ-V scores was significant at .0005 level of significance for a one tailed test $(\mathrm{N}=18, T=-3.333, p=.0005$ for a one tailed test), implying that scores on the GHSQ-V were better at post test than at pre test. The participants had higher intentions to seeking help from psychotherapists and other professional mental health care providers than they used to. Thus, this hypothesis was supported by the data collected. This indicated that the intervention worked positively. This is congruent with the findings of Gulliver, Griffiths, Christensen and Brewer (2012), whose review of studies on interventions at improving help seeking revealed that interventions that utilized cognitive behavioral therapy and personalized feedback about the individual's symptoms significantly improved help seeking intentions in the intervention group compared with that of the control group than the other interventions like mental health literacy.

Hypothesis 2: It was also hypothesized that participants will report an increase in their actual help seeking behavior after the intervention.

The purpose of this hypothesis was to find out whether psychotherapists could improve help seeking behavior with psychotherapy. The data collected was analyzed using the Wilcoxon Matched-Pairs Signed-Ranks $(T)$ Test with the SPSS software.

The means and standard deviations (extracted from the SPSS output) are shown in Table 3.

Table 3. Means and Standard Deviation of Pre-Test and Post-Test Scores on Help Seeking Behavior

\begin{tabular}{lccc}
\hline Gender & Mean Score & Std. Dev. & Sample Size (n) \\
\hline Pre Test (AHSQ) & 17.4444 & 2.00653 & 18 \\
Post Test (AHSQ) & 15.7222 & 3.15866 & 18 \\
\hline
\end{tabular}

Source: Field Study

The data was further analyzed with the Wilcoxon Matched-Pairs Signed-Ranks ( $T$ ) Test to determine whether the differences in the means were significant. Table 4 presents a summary table of the Wilcoxon Matched-Pairs Signed-Ranks $(T)$ Test for the dependent variable.

Table 4. Summary Table of the Wilcoxon Matched-Pairs Signed-Ranks (T) Test Performed on the Data Presented in Table 3

\begin{tabular}{lcccc}
\hline Group & Mean Rank & Sum of Ranks & $\boldsymbol{T}$ & $\boldsymbol{p}$ (level of Significance) \\
\hline Pre Test (AHSQ) & 8.61 & 77.50 & & \\
Post Test (AHSQ) & 3.38 & 13.50 & -2.253 & $p<.012$ (one tailed) \\
\hline
\end{tabular}

Source: Field study

Table 4 clearly shows that the computed value of $T$ for the AHSQ scores was significant at .012 level of significance for a one tailed test $(\mathrm{N}=18, T=-2.253, p=0.012$ for a one tailed test). This portrayed that respondents had a significant increase in their help seeking behavior after the intervention (at post test). Subjects scored better on the AHSQ at post test than at pre test. Thus the hypothesis was confirmed.

This finding supports the findings of Barker's (2007), which indicated that program efforts and policy initiatives aimed at promoting help seeking behavior had been useful. This is also consistent with the results of a study by Santor, Poulin, LeBlanc and Kusumakar (2006), whose research into increasing help seeking behavior among the youth concluded that help seeking for mental distress could be promoted through workshops to address the importance of help seeking. It is also congruent with the findings of Gulliver, Griffiths, Christensen and Brewer (2012), whose review of studies on interventions at improving help seeking revealed that interventions that used cognitive behavior therapy with the aim of promoting help seeking behavior had been worthwhile.

\subsection{Summary of Findings/Conclusions}

The results from the study suggested that psychotherapists could improve help seeking behavior with cognitive, insight and supportive therapies. This study has contributed enormously to previous knowledge in that the effectiveness of cognitive, insight and supportive therapies in improving help seeking behavior is an important finding that is applicable and exploitable.

\subsection{Implications from the Study}

The information will be of importance to clinical psychologists, school psychologists/counselors and other social workers dealing with young people. School psychologists/counselors desiring to provide better care for their counselees or to increase students patronizing their services should consider ways of promoting help seeking behavior.

\subsection{Limitations of the Study}

Despite its relevance to society and its vital implications, the study has some limitations. This study used the 
non-probability sampling method to recruit its respondents instead of the simple random sampling technique. Also, considering how strong the issue of stigma could be, respondents could have been reluctant to honestly appraise their help seeking behaviors and intentions thus providing socially desirable answers which could have influenced the outcome of the study. Respondents were however assured confidentiality and given unconditional positive regard so probably this shortfall may not have had much negative impact on this study's outcome.

\subsection{Suggested Areas for Future Research}

The following areas are recommended to be studied for future research:

- Studies to explore the help seeking behavior of Ghanaian students in primary and or in junior and senior high schools,

- Other psychotherapeutic interventions (like Freud's psychoanalysis e.t.c.) and their impact on improving mental health service utilization are also recommended to be studied.

\section{Acknowledgement}

First and foremost, I thank the Almighty God for giving me strength to accomplish this research. I gratefully acknowledge analytical inputs to this study made by Prof. S. A. Danquah, Prof. J. Y. Opoku and Dr. B. Amponsah all of the Department of Psychology, University of Ghana, Legon. Special acknowledgment also goes to the participating institution and its respective respondents. I thank you all for your help and support.

\section{References}

[1] Appiah-Poku, J., Laugharne, R., Mensah, E., Osei. Y. and Burns, T. (2004). Previous help sought by patients presenting to mental health services in Kumasi, Ghana. Social Psychiatry and Psychiatric Epidemiology, (39) 3. 208-211.

[2] Auglin, D. M., Alberti P. M., Link, B. G. \& Phelan, J. C. (2008). Racial differences in beliefs about the effectiveness and necessity of mental health treatment. American Journal of Community Psychology. 42(1-2):17-24.

[3] Barker, G. (2007). Adolescents' social support and help seeking behavior. World Health Organization (WHO).

[4] Boyraz, G., Horne, S., Owens, A. \& Armstrong, A. (2013). Academic achievement and college persistence of African American students with trauma exposure. Journal of Counseling Psychology. Advance online publication. doi: 10.1037Counseling

[5] Britten, N. (1998). Psychiatry, stigma, and resistance: psychiatrists need to concentrate on understanding. Not simply compliance. British Medical Journal 317. 763-764.

[6] Cornally, N. \& McCarthy, G. (2011). Help-seeking behavior: A concept analysis. International Journal of Nursing Practice. 17: 280-288
[7] Garcia, M., \& Rodriguez, P. F. (1989). Psychological effects of political repression in Argentina \& El Salvador. In D. Koslow \& E. Salett (Eds.), Crossing Cultures in Mental Health (pp. 64-83). Washington, DC: SIETAR International.

[8] Gulliver, A., Griffiths, K. M. Christensen, H. B. \& Brewer, J. L. (2012). A systematic review of help-seeking interventions for depression, anxiety and general psychological distress. Bio-med Central Psychiatry, 2012, 12:81

[9] Gulliver, A., Griffiths, K. M. \& Christensen, H. B. (2010). Perceived barriers and facilitators to mental health help seeking in young people: a systematic review. Bio-med Central Psychiatry, 2010, 10:113

[10] Howerton, A., Byng, R., Campbell, J., Hess, D., Owens, C. \& Aitken, P. (2007). Understanding help seeking behavior among male offenders: Qualitative interview study. British Medical Journal, 334 (7588).

[11] Kessler, R. C., Brown, R. L. \& Broman, C. L. (1981). Sex differences in psychiatric help-seeking: evidence from four large-scale surveys. Journal of Health and Social Behavior, 22(1), 49-64.

[12] Kwong, K. (2011). Increasing access to mental health services and assessing help seeking behavior of depressed Chinese-American patients in primary care - A Feasibility Pilot Study. Society for Social Work and Research.

[13] Mackenzie C. S., Pagura J. \& Sareen J. (2010). Correlates of perceived need for and use of mental health services by older adults in the collaborative psychiatric epidemiology surveys. American Journal of Geriatric Psychiatry, 18(12), 1103-15.

[14] Miranda, J. \& Green, B. L. (1999). The need for mental health services research focusing on poor young women. The Journal of Mental Health Policy and Economics, 2, 73-80.

[15] Moloczij, N. McPherson K. M., smith J. F. \& Kayes N. M. (2008). Help seeking at the time of stroke: Stroke survivor's perspective on their decisions. Health and Social Care in the Community, 16, 501-510.

[16] Nelson-Le Gall, S. (1985). Help-seeking behavior in learning. In E. W. Gordon (Ed.), Review of Research in Education (Vol. 12, pp. 55-90). Washington, DC: American Educational Research Association.

[17] Ofori-Atta, A., Cooper, S., Akpalu, B., Osei, A., Doku, V., Lund, C. and the Mhapp research Program Consortium (2010). Common understandings of women's mental illness in Ghana: Results from a qualitative study, International Review of Psychiatry. (22) 6: 589-98.

[18] Opoku, J. Y. (2006). Tutorials in inferential social statistics (2nd Ed.). Accra: Ghana Universities Press.

[19] Pattenden, J., Watt, I., Lewin, R. J. P. \& Standord, N., (2002). Decision making process in people with symptoms of acute myocardial infarction: Qualitative study. British Medical Journal, 324, 1-5.

[20] Read, U. \& Doku, V. C. K. (2012). Mental health research in Ghana: A literature review. Ghana Medical Journal, 46 (SO), 29-38.

[21] Rickwood, D. J. \& Braithwaite, V. A. (1994). Social-psychological factors affecting seeking help for emotional problems. Social Science and Medicine, 39, $563-572$. 
[22] Santor, D. A., Poulin, C., LeBlanc, J. C. \& Kusumakar, V. (2006). Facilitating help seeking behavior and referrals for mental health difficulties in school aged boys and girls: A school-based intervention. Journal of Youth Adolescence. 39, 729-735.

[23] Schreiber, V., Maercker, A., \& Renneberg, B. (2010). Social influences on mental health help seeking after interpersonal dramatization: A qualitative analysis. BMC Public Health, 10, 634-642.

[24] Turner, J., Midgley, C., Meyer, D. K., Gheen, M., Anderman, E. M., Kang, Y. \& Patrick, H. (2002). The classroom environment and students' reports of avoidance strategies in mathematics: A multi-method study. Journal of Educational Psychology, 94, 88-106.

[25] Wang, P. S., Berglund, P. A., Kessler, R. C., Olfson, M., Pincus, H. A. \& Wells, K. B. (2005). Failure and delay in initial treatment contact after first onset of mental disorders in the National Comorbidity Survey Replication (NCS-R). Archives of General Psychiatry, 62(6), 603-613.

[26] Wilson, C. J., Deane, F. P., Ciarrochi, J. V. \& Rickwood, D. (2005). Measuring help-seeking intentions: Properties of the General Help-seeking Questionnaire. Canadian Journal of Counselling, 39, 15-28. 